Portland State University

PDXScholar

Summer 2020

\title{
Socio-Emotional Learning as a Core Standard in Early Education: Producing Competent Adults
}

Talia Maras

Portland State University

Follow this and additional works at: https://pdxscholar.library.pdx.edu/honorstheses

Part of the Early Childhood Education Commons, School Psychology Commons, and the Social Psychology Commons

Let us know how access to this document benefits you.

\section{Recommended Citation}

Maras, Talia, "Socio-Emotional Learning as a Core Standard in Early Education: Producing Competent Adults" (2020). University Honors Theses. Paper 952.

https://doi.org/10.15760/honors.975

This Thesis is brought to you for free and open access. It has been accepted for inclusion in University Honors Theses by an authorized administrator of PDXScholar. Please contact us if we can make this document more accessible: pdxscholar@pdx.edu. 


\title{
Socio-Emotional Learning as a Core Standard in Early Education: Producing Competent Adults
}

\author{
by \\ Talia Maras
}

An undergraduate honors thesis submitted in partial fulfillment of the requirements for the degree of Bachelor of Science

in

University Honors

and

Psychology and Social Sciences

Thesis Advisor

Sherrie Campbell, Ph.D

Portland State University

2020 


\begin{abstract}
A child's foundational emotional proficiency is highly predictive of their academic success. It is therefore imperative that center-based, federally funded, public childhood education systems provide their students with a curriculum that facilitates the development of a strong socio-emotional baseline on which to build their cognitive, academic abilities. Drawing on government reports by the US Department of Education and empirical publications from an academic perspective, this paper reviews the nature of current efforts to reform the childhood education system, as seen through the implementation of the common core standards of learning. I review the quality of education that is provided by curricula which involve these common core standards, and criticize the many faults that largely contribute to the academic achievement gap. This literature review indicates that directly addressing the risk factors which have frequent detrimental effects on childhood social and emotional development is the most effective way to improve overall academic success in the United States. This paper encourages the implementation of SEL in public academic settings in effort to provide children with a strong baseline of social and emotional skill which will structure their academic success as well as advise them through the trials of self-regulation in adolescence and support competency in adulthood.
\end{abstract}




\section{Socio-Emotional Learning as a Core Standard in Early Education: Producing}

\section{Competent Adults}

It is widely agreed upon by many experts that a child's level of emotional fluency and security in their own emotional abilities is directly predictive of their quality of academic achievement and behavioral management in the context of school (Brouzos et al., 2014). Children who score higher on measures of emotional intelligence are more focused and engaged in school, have stronger, more supportive relationships, and are more empathic. Those who have acquired the ability to regulate their emotionally-based behaviors earn higher grades and are more resilient overall (Flook et al, 2015; Krashen, 2014; McClelland et al., 2017; Tominey et al., 2017).

Despite these compelling, widely endorsed findings, in 2009 the Council of Chief State School Officers and the National Governors Association implemented the "common core" standards of learning on a federal level in an effort to close the academic achievement gap in elementary and high school students—without taking into account the pivotal role of socio-emotional development in said achievement. The purpose of this direction in reform was to hold all students to an extremely high standard of learning, regardless of the level of risk to which an individual may be exposed (U.S. Department of Education [USDE], 2019).

In response to the implementation of federally mandated learning standards within curricula and the consequent series of common core assessment drills, teacher and political activist Stephen Krashin points out that the true problem regarding public education is not that students are not being held to a high enough standard. Numerous 
studies from the pedagogical and social sciences identify individual as well as systemic risk factors as the reasons for the wide academic achievement gap (Krashen, 2014; McClelland et al., 2017). Students who are underperforming academically are likely at-risk due to conditions such as abuse or poverty. Moreover, these underperforming students will likely do even worse under heightened pressure (Flook et al, 2015; Krashen, 2014; McClelland et al., 2017).

Another apparent dysfunction related to the common core program is that there are only three subject areas that it directs rigorous and obsessive attention towardsreading, language arts, and mathematics (Common Core State Standards Initiative [CCSSI], 2020); all three of these standards emphasize the development of cognitive abilities, which is only one of several competency skill sets necessary in the development of a functional adult. While the US Department of Education claims that the actual adoption of common core standards into school curricula is up to the state's decision, this is not entirely true. It appears that if a state decides that they would not like to implement common core, the federal government will withhold a substantial amount of funding from their school districts (USDE, 2019). Thus far, there are 16 states that have refuted common core (Ujifusa et al., 2017). The money that is granted to the state in compliance with the adoption of common core is typically likely to only pay off huge scholastic corporations—such as Pearson and McGraw Education-for the creation of the many interim common core assessment tests. For example, it has been found that the $\$ 669$ million in collective state annual spending was funneled into six private vendors (Ujifusa, 2012). In other words, schools often actually have less control 
over their curricula due to selective funding, or they are being forced to pour all of their funding into building assessment tests which accurately reflect the assessment of common core standards, as interpreted by the state's standards of curricula.

Despite the efforts of the United States government to reform the education system to produce more well-rounded and competent adults, many experts believe that there is still much more work to be done. In this thesis, I ask: how can schools better provide children with the tools they need to become more well-rounded, competent adults?

\section{Review of SEL Literature}

As mentioned previously, common core is only focused on enhancing academic achievement in three areas: mathematics, language arts, and writing (CCSSI, 2020). While many experts would agree that mathematics, language arts, and writing are three areas of academic achievement which should be prioritized in childhood education, it is also agreed upon that they are not the only areas of achievement that play a major role in developing a healthy, well-rounded, competent human being. As children are particularly impressionable during this developmental period, it is the ideal time to expose them to crucial knowledge regarding interpersonal relationships, emotional processes, and cognitive regulation (Flook, et al., 2015; McClelland et al., 2017).

\section{Defining Characteristics and Limitations of Socio-Emotional Learning}

Social and emotional learning (SEL) can be implemented into schools as a preventative measure to combat risk factors for children by teaching them how to cope with stress and build support systems (Flook et al, 2015; McClelland et al., 2017). In this 
section, I will outline the defining characteristics of SEL, demonstrate popular variations of SEL in early education, and describe the limitations that are frequently met in the realization of these variable programs.

\section{Characteristics of Socio-Emotional Competence}

1. Emotional Processes. Emotional processes include sub-skills such as emotional knowledge, emotional regulation, perspective taking, and empathy. The ability to recognize and label emotions accurately is crucially important for effective basic communication.

(McClelland et al., 2017) To be aware and understand how oneself feels is a baseline skill that acts as a foundation on which to build strong introspective skills, self-care values, and a strong personal identity. Additionally, the ability to understand a perspective that is an alternative to their own allows children to develop cooperation and conflict resolution skills which are critical to healthy behavioral functioning.

2. Interpersonal skills. These skills involve behavioral-communicative sub-skills which promote positive, constructive interactions with others.(McClelland et al., 2017). The development of emotional knowledge which allows a child to recognize social cues and correctly interpret the intentions behind other's behaviors will promote agreeableness in personality formation, as well as serve as a baseline to develop protective social support and positive peer relationships.

3. Cognitive regulation. The third main component of SEL focuses on cognitive flexibility, working memory, and inhibitory control. Cognitive regulation skills such 
as these help children focus on what they are doing, teach them how to comfortably shift their attention between tasks, inhibit impulses, and listen to/remember instructions (McClelland et al., 2017).The implication of the development of these skills in childhood is of obvious importance, especially when put into the context of school and early education.

Unfortunately, this particular aspect of SEL appears to have been widely neglected, when considering the current childhood ADHD epidemic in the United States specifically. Perhaps the current overdiagnosis of ADHD does not in fact reflect an irresponsibly lenient diagnostic criteria, but instead points to a bigger, more systematic issue. With the current school learning standard criteria, the development of executive functioning skills is not at all prioritized. Children are suffering psychological ailments as a result of this negligence, as the diagnostic trends for ADHD development in early childhood has skyrocketed within the last few decades. This is one of the many examples of how the current federally mandated learning standards for childhood education pushes schools to lessen their emphasis on teachable baseline skills (such as executive functioning), and over-prioritize knowledge that is unattainable without the provision of these aforementioned SEL skills.

\section{Theoretical Variations of SEL}

\section{Social Learning and Pretend Play Models}

Like many early education intervention programs, SEL is based on research which follows specific theoretical perspectives. Some variations of these interventions 
may have set standards of learning which may be taught in center-based institutions, similar to common core. These types of interventions may be based on principles such as the social learning theory and pretend play models of learning (McClelland et al., 2017). SEL interventions which are based on social learning theory models focus on children's interpersonal competency in the interpretation and responses of social challenges. Privately developed programs such as PATHS, REDI, KITS, and ICPS have had positive impacts on socio-emotional skills such as cognitive regulation, problem solving in social situations, and have decreased risks such as antisocial behaviors and aggression (McClelland et al., 2017).

Limitations. While these independent programs are credited by many experts to have had positive results, the actual implementation of them nationally is unrealistic, as most states face financial restrictions as well as lack of support on both a private and federal level. Unfortunately, the fact that most states struggle to integrate these programs deeply implies that the states which have the highest risk populations (and are therefore in the most desperate need of risk prevention programs) may find it impossible to fund a second, supplementary curriculum if it is not federally financed.

\section{Coercion theory}

Other effective variations of SEL intervention programs may employ the coercion theory which indirectly establishes socio-emotional skills in children through teaching and communication methodology. Teachers are encouraged to manage their classrooms by building positive relationships with their students, thereby modeling and encouraging the development of interpersonal and self regulatory skills. This form of 
SEL may be more difficult to establish because it requires specialized knowledge of child educators in not both the content and practice of SEL (McClelland et al., 2017). This theoretical variation of SEL is especially interesting, as it appears to mimic positive interventions for parenting behavioral education. Several popular parenting education interventions focus on a set list of positive parental behaviors. Johnson et. al. has provided a clearly outlined model of parenting competencies with their appropriate behavioral counterparts, Foundational and Functional Parenting Competencies and Subcompetencies with Behavioral Anchors by Proficiency Level (Johnson et al., 2014, appx.). Although the competencies and behaviors listed in this model were meant to provide a standardized framework for parenting education programs, it can also be applied to a variety of other educational and behavioral interventions due to its generalizability and allowance for cultural adjustments. Additionally, many of the competencies listed in this model directly reflect the learning standards for most SEL early childhood education interventions, although in this model, they are separated into two distinct competency categories: foundational competencies and functional competencies.

Foundational competencies refer to the knowledge, skills, attitudes, and values that underlie the performative functions of a given task. Foundational skills and competencies are typically pedagogical and learned through intergenerational interactions at a developmentally impressionable age. They are meant to provide a hypothetical off of which to build functional competencies. Functional competencies are 
characterized by the actual, learned ability to perform the task itself (Johnson et al., 2014).

Limitations. It is through the categorization of these competencies in which the limitations of coercive SEL become clear. In order for instructors to adequately learn the functional skills needed to perform this method of SEL, they must have already established a prior foundational framework for those competencies (Johnson et al., 2014). In other words, an instructor who is assigned to undergo additional training to perform coercive SEL, must have acquired baseline competencies in many areas which are not taught in schools, such as psychological health, self-care, and certain aspects of cognitive ability.

\section{Conclusions and Recommendations for Future Work}

The purpose of government involvement within education should be to assist schools in their efforts to provide children with the tools they need to succeed into adulthood. According to the National Center for Children in Poverty, 15 million children $(21 \%)$ in the United States live in families who receive income below the poverty threshold (2019). Not only should schools be focusing on setting students on a constructive track towards receiving a college education, they should also be offering competence in the skills and attributes necessary to cope with risk factors which may inhibit their academic performance.

By providing the skills necessary to combat the threat of risk factors -such as poverty- for all students, we narrow the achievement gap, lower the need for the implementation of expensive individualized intervention programs, and provide children 
with the skills that they need to make competent behavioral decisions regarding their personal development and education into and throughout adulthood (Krashen, 2014; McClelland et al., 2017).

While the actual implementation of SEL programs has proven to be tricky due to government restrictions, lack of funding, as well as a lack of competent instructor training, SEL, when implemented, has still been proven to enhance academic performance in children (Greenberg et al., 2017).

As informed by the research mentioned throughout this report, my recommendation to support the strong implementation of SEL on a national level would be to lessen the emphasis of assessment on the current common core curricular standards in effort to supplement the implementation of foundational SEL standards. These standards should be held to the same importance as the currently recommended common core cognitive/academic standards.

Providing children with SEL foundational competencies such as psychological health, self-care, interpersonal relationships, and intrinsic aspects of cognitive abilities will ensure that all American students will have had formal training in basic emotional competency and self regulatory skills, thus standardizing a baseline social and emotional competency for the next generation of covert SEL educators. 


\section{References}

Brouzos, A., Misailidi, P., \& Hadjimattheou, A. (2014). Associations between emotional intelligence, socio-emotional adjustment, and academic achievement in childhood: The influence of age. Canadian Journal of School Psychology, 29(2), 83-99. https://doi.org/10.1177/0829573514521976

Common Core State Standards Initiative (2020). Read the standards. http://www.corestandards.org/read-the-standards/

Flook, L., Goldberg, S. B., Pinger, L., \& Davidson, R. J. (2015). Promoting prosocial behavior and self-regulatory skills in preschool children through a mindfulness-based kindness curriculum. Developmental Psychology, 51(1), 44-51. http://dx.doi.org.proxy.lib.pdx.edu/10.1037/a0038256

Greenberg, M., Domitrovich, C., Weissberg, R., \& Durlak, J. (2017). Social and emotional learning as a public health approach to education. The Future of Children, 27(1), 13-32. www.jstor.org/stable/44219019

Johnson, B. D., Berdahl, L. D., Horne, M., Richter, E. A., \& Walters, M. G. (2014). A parenting competency model. Parenting, 14(2), 92-120. https://doi.org/10.1080/15295192.2014.914361

Krashen, S. (2014). The common core: A disaster for libraries, a disaster for language arts, a disaster for American education. Knowledge Quest, 42(3), 37-45. http://www.schoolsmatter.info/2014/01/the-common-core-disaster-for-libraries.ht $\underline{\mathrm{ml}}$ 
McClelland, M. M., Tominey, S. L., Schmitt, S. A., \& Duncan, R. (2017). SEL interventions in early childhood. The Future of Children, 27(1), 33-47. https://www.jstor.org/stable/44219020?pq-origsite=summon\&seq=1\#metadata_in fo tab contents

National Center for Children in Poverty (2019). Child poverty. http://www.nccp.org/topics/childpoverty.html

Tominey, S. L., O’Bryon, E. C., Rivers, S. E., \& Shapses, S. (2017). Teaching emotional intelligence in early childhood. Young Children, 72(1). https://www.naeyc.org/resources/pubs/yc/mar2017/teaching-emotional-intelligenc $\underline{\mathrm{e}}$

Ujifusa, A. (2012). Standardized testing costs states $\$ 1.7$ billion a year, study says. Education Week, 32(13). https://www.edweek.org/ew/articles/2012/11/29/13testcosts.h32.html

Ujifusa, A., Bannerjee, S., \& Tomko, G. (2017). Map: Tracking the common core state standards [Infographic]. Education Week, 36(11), 16. https://www.edweek.org/ew/section/multimedia/map-states-academic-standardscommon-core-or.html

U.S. Department of Education (2019). College- and career-ready standards. https://www.ed.gov/k-12reforms/standards 